\title{
(i) In vitro-In vivo Drug Interaction Study of Paracetamol and Propranolol Hydrochloride
}

\author{
Jyothigoudapura Channabasappa Thejaswini, Bannimath Gurupadayya* and \\ Venkata Sairam Koganti \\ Department of Pharmaceutical Chemistry, JSS College of Pharmacy, JSS University, Mysuru, Karnataka, \\ India.
}

\begin{abstract}
Introduction: Propranolol Hydrochloride is a non-cardio selective beta-adrenergic antagonist, used in the treatment or prevention of many disorders, including acute myocardial infarction, arrhythmias, angina pectoris, hypertension, hypertensive emergencies, hyperthyroidism and migraine. Paracetamol is an antipyretic agent which is also known for its analgesia and is concurrently administered to patients who are on treatment with propranolol hydrochloride in the management of migraine. Objective: In the present work, an in vitro and in vivo drug interaction was assessed to establish the relationship between drug dissolution and plasma drug concentration and pharmacokinetics of selected drugs. Method: In vitro drug release studies were performed in simulated gastric juice $(\mathrm{pH}$ 1.2). The in vitro drug dissolution and changes in plasma concentration of the drugs in vivo in Wistar rats were determined individually and in the presence of other drug at different time interval. Results: A significant delay in the dissolution of propranolol hydrochloride in the presence of paracetamol was observed and the paracetamol dissolution was prolonged in the presence of propranolol hydrochloride. $t_{\max }$ of propranolol Hydrochloride was prolonged and extended $\mathrm{t}_{1 / 2}$ was found when propranolol hydrochloride was administered with paracetamol concurrently. A delay in $t_{\max }$ of paracetamol and shortened $t_{1 / 2}$ was observed. Conclusion: The results show the existence of correlation between in vitro drug dissolution and in vivo plasma concentration and the corresponding pharmacokinetics of propranolol hydrochloride and paracetamol.
\end{abstract}

Key words: Correlation, Drug interaction, In vitro-In vivo, Propranolol hydrochloride, Paracetamol.

\section{INTRODUCTION}

Migraine is one of the top 10 most disabling disorders worldwide. ${ }^{1}$ Migraine generally signified as a common headache disorder with significant physical, mental, and social health consequences which is generally influenced by

\begin{tabular}{|c|c|}
\hline \multicolumn{2}{|c|}{ Access this article online } \\
\hline Journal Sponsor & \multirow[b]{2}{*}{$\begin{array}{l}\text { Website: } \\
\text { www.jyoungpharm.org }\end{array}$} \\
\hline \multirow{2}{*}{ www.phcog net } & \\
\hline & $\begin{array}{l}\text { DOI: } \\
\text { 10.5530/jyp.2015.4s.10 }\end{array}$ \\
\hline
\end{tabular}

peptidergic, adrenergic, and serotonergic systems. ${ }^{2}$ Occipital epilepsy and migraine though they are different disorders, they have the common symptoms. In addition acute attack treatment, drug prophylaxis of migraine is significant in order to improve the quality of life. Calcium channel blockers, beta blockers, anticonvulsants etc. have been used in migraine prophylaxis since $1970 .{ }^{3}$ Propranolol hydrochloride is the drug of choice in migraine management which acts by vasodilation. ${ }^{4}$ Adjuvant drugs, such as paracetamol and anti-inflammatory agents, which through physiological or pharmacological synergism, enhance pain control are prescribed along with prophylactic drugs. ${ }^{5}$

\footnotetext{
*Address for correspondence:

Prof. Bannimath Gurupadayya, Department of Pharmaceutical Chemistry JSS College of Pharmacy, JSS University, Sri

Shivarathreeswara Nagar, Mysuru-570 015, Karnataka, India.E-mail: bmgurupadayya@jssuni.edu.in
} 


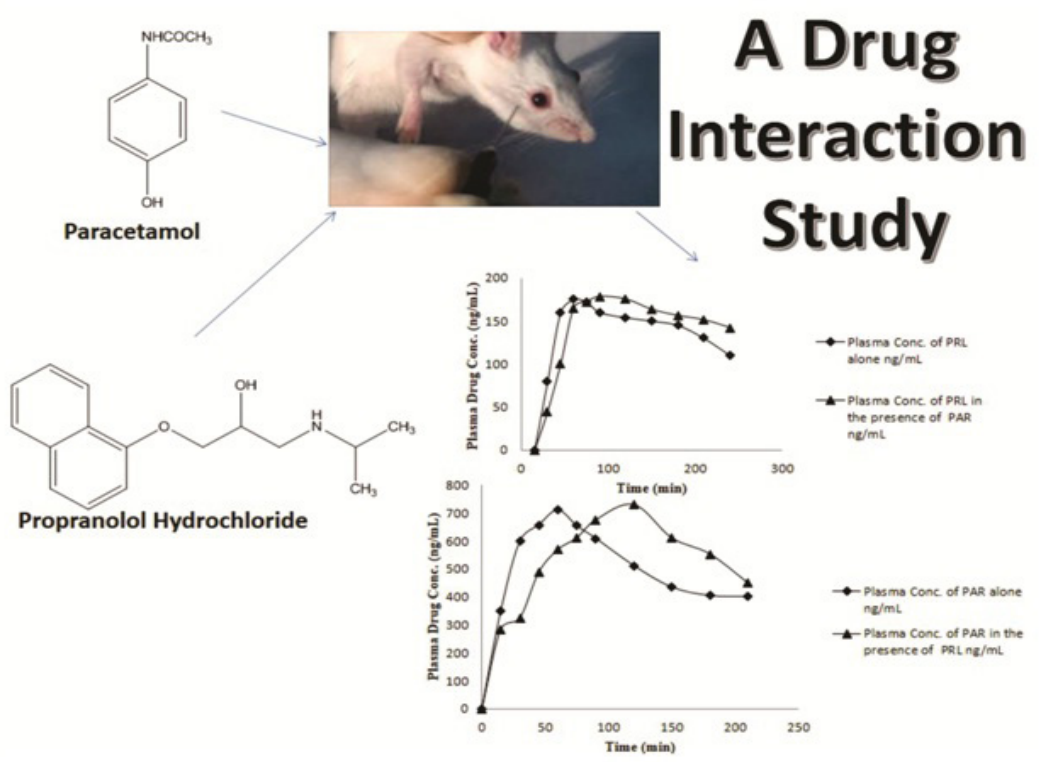

Graphical Abstract

Many studies have confirmed polypharmacy as one of the major risk factors in precipitation of PDDIs (potential drug-drug interactions). ${ }^{67}$ The elderly populations are at increased risk because of decreased functioning of the systems, more number of medications due to comorbidities, and complicated drug regimens. ${ }^{8,9}$ When two drugs are concomitantly administered through oral route, the dissolution pattern of one drug may affect the dissolution of the other. During poly pharmacy there may be increased or decreased acidity in gastric environment and hence degree of ionization of one drug in the presence of other in stomach $\mathrm{pH}$ may get altered which affects the disintegration and dissolution of tablet dosage forms. Subsequently the plasma concentration of drugs may get altered and lead to toxic side effect or therapeutic inefficiency. Hence the present study was designed to assess the drug interaction between Propranolol Hydrochloride and Paracetamol in vitro and in vivo.

\section{MATERIALS AND METHODS}

\section{Drugs and chemicals}

Propranolol hydrochloride and paracetamol were purchased from Balaji drugs, Ahmadabad. HPLC grade solvents (acetonitrile and methanol) and analytical grade potassium dihydrogen phosphate were purchased from Sigma Aldrich (Bangalore, India). Millipore water was used for the preparation of drug solutions. Propranolol hydrochloride Tablet (Inderal $80 \mathrm{mg}$ ) and Paracetamol (Crocin $500 \mathrm{mg}$ ) were purchased from local retail drug store, Mysuru.

\section{Methodology}

In vitro drug interaction study

In vitro drug release studies were performed by using a Shimadzu USP dissolution rate apparatus (apparatus 2, $100 \mathrm{rpm}, 37 \pm 0.5^{\circ} \mathrm{C}$ ) at $\mathrm{pH} 1.2$ (simulated gastric fluid). The test samples were withdrawn at different time intervals and measured by RP-HPLC method.

To the dissolution paddles containing $900 \mathrm{~mL}$ of dissolution medium (simulated gastric fluid of $\mathrm{pH}$ 1.2) previously maintained at $37^{\circ} \mathrm{C}$, a single tablet of propranolol hydrochloride and Paracetamol were added individually and in the presence of the other. Aliquots of test solutions were withdrawn at 10 min interval for 150 min, diluted suitably and the percentage drugs dissolved at different time interval were calculated by a validated RP-HPLC method. A comparison between the percentage dissolution of propranolol hydrochloride and paracetamol in the presence of other drug was made by plotting a graph of percentage drug dissolution against time interval.

\section{In vivo drug interaction study}

Institutional ethical committee approval was obtained prior to the conduct of the drug interaction study. Wistar rats of either sex weighing between 150-250 gm procured from Sri. Raghvendra Enterprises, Bangalore (CPCSEA Reg No $841 / \mathrm{b} / 04 / \mathrm{CPCSEA}$ ) were used in the study. They were maintained under standard husbandry conditions in the institutional animal house at an ambient temperature with $12 \mathrm{hr}$ light/12 hr dark cycles. They were fed with standard pellet diet and water ad libitum. Animals were fasted for 18 


\begin{tabular}{|c|c|}
\hline Study Group & Study drug \& Dose \\
\hline G1 (Control) & No administration \\
\hline G2 (PAR) & Paracetamol oral single dose \\
\hline G3(PRL) & $\begin{array}{c}\text { Propranolol Hydrochloride oral single } \\
\text { dose }\end{array}$ \\
\hline G4 (PRL and PAR) & $\begin{array}{l}\text { Propranolol Hydrochloride and } \\
\text { Paracetamol oral single dose }\end{array}$ \\
\hline
\end{tabular}

hrs before the interaction study and during the interaction study, food and water were withdrawn.

The rats of were divided into three groups G1, G2 and G3 respectively. Group G1 was considered to be a control group (Table 1). Group G2 was administered with 2.8 $\mathrm{mg} / 200 \mathrm{~g}$ of body weight of propranolol hydrochloride and G3 was administered with $17.5 \mathrm{mg} / 200 \mathrm{~g}$ of body weight of paracetamol orally. $0.3 \mathrm{~mL}$ of the blood samples was withdrawn by retro orbital puncture at the end of 0 , $15,30,45,60,75,90,120,150,180,210$ and 240 min into heparinized tubes..$^{10} 1 \mathrm{~mL}$ of acetonitrile was added as protein precipitating agent. Blood samples were centrifuged at $6000 \mathrm{rpm}$ for $5 \mathrm{~min}$. The supernatant was filtered using $0.2 \mu \mathrm{m}$ PTFE syringe filter and $10 \mu \mathrm{L}$ was transferred to Liquid Chromatograph. The concentration of propranolol hydrochloride and paracetamol were determined in each plasma sample using a validated RP-HPLC method.

HPLC analysis

Shimadzu HPLC (LC Solution handling system) with LC-2010 $A_{\mathrm{HT}}$ prominence liquid chromatography with PDA detector was employed for the present study. Data acquisition and processing was done using LC solution software.

Elution was carried out on $\mathrm{C}_{18}(250 \times 4.6 \mathrm{~mm} .5 \mu)$ Phenomenex column and a mixture of acetonitrile with

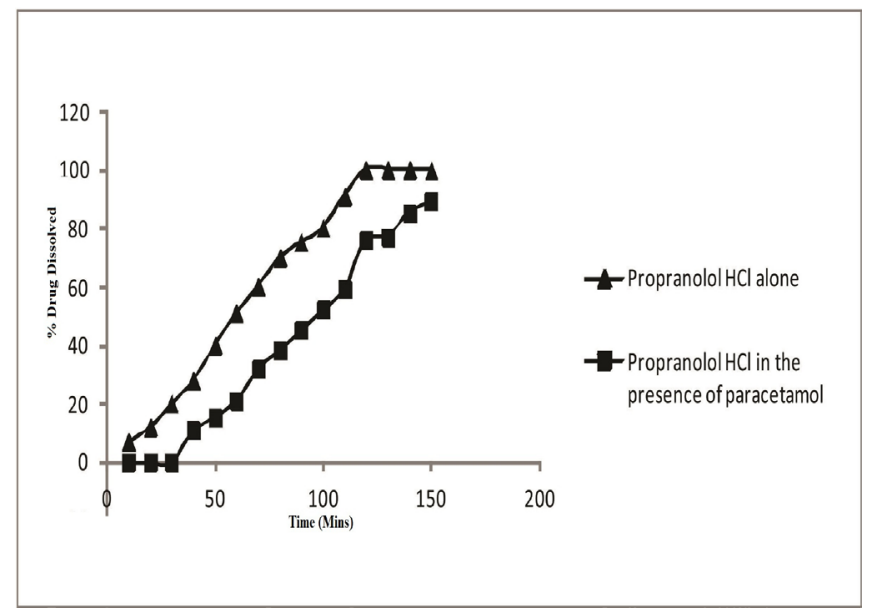

Figure 1: In vitro drug interaction studies of propranolol hydrochloride alone and in propranolol hydrochloride presence of paracetamol phosphate buffer $\mathrm{pH}-7(40: 60)$ at a flow rate of $1 \mathrm{~mL} /$ min was used as mobile phase. Elutes were monitored at 210 nm with Prominence PDA detector. Percentage drug dissolution and plasma drug concentrations were calculated at different time intervals using standard calibration curves.

Analysis of pharmacokinetic parameters

Pharmacokinetic parameters of propranolol hydrochloride and paracetamol when administered to experimental rats individually and concurrently were characterized by peak concentration in plasma $\left(\mathrm{C}_{\max }\right)$, maximum peak time $\left(\mathrm{t}_{\max }\right)$, area under the curve $\mathrm{AUC}(0-\mathrm{t}), \mathrm{AUC}_{0 \rightarrow \infty}$, elimination rate constant $(\mathrm{Kel})$, clearance $(\mathrm{Cl})$ using non compartment model. The pharmacokinetic parameters were derived using PK solver software. Results are expressed as mean \pm SD.

\section{Statistical analysis}

The Percentage drug dissolution, plasma drug concentration and pharmacokinetic variables were compared with pooled $T$ test. The level of statistical significance was $\mathrm{p}<0.05$.

\section{RESULTS}

\section{In vitro interaction study}

In acid buffer solution of $\mathrm{pH} 1.2,7 \%$ of propranolol hydrochloride appeared at the end of 10 minutes and gradually its dissolution percentage increased and its 100 $\%$ dissolution was observed at the end of 120 minutes. Interestingly, propranolol hydrochloride when dissolved in the presence of paracetamol, at the end of 40 minutes, only $11.1 \%$ was dissolved and even at the end of $150 \mathrm{hrs}$ showed $89 \%$ dissolution (Figure 1). This change in dissolution of propranolol hydrochloride in the presence and absence of paracetamol showed a $\mathrm{p}$ value of 0.045 .

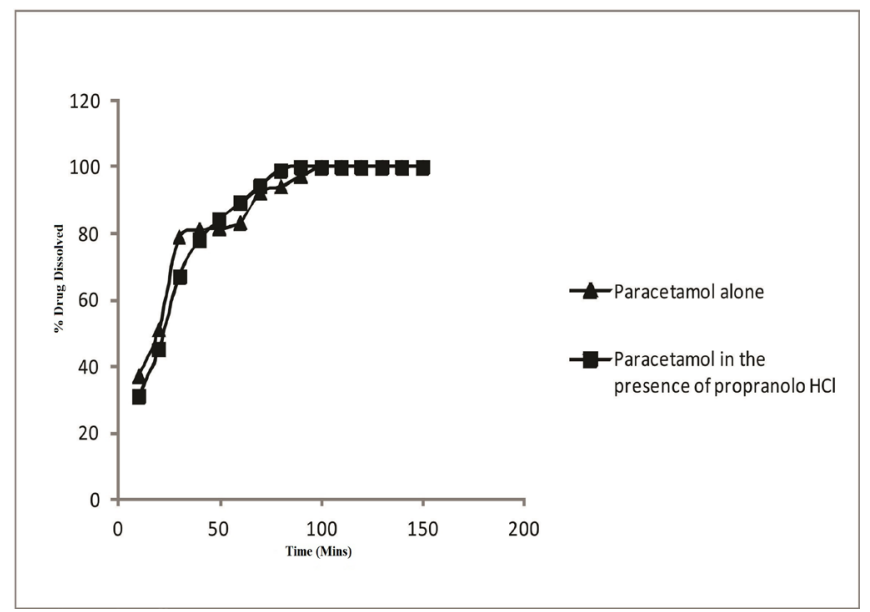

Figure 2: In vitro drug interaction studies of paracetamol alone and in paracetamol presence of propranolol hydrochloride 


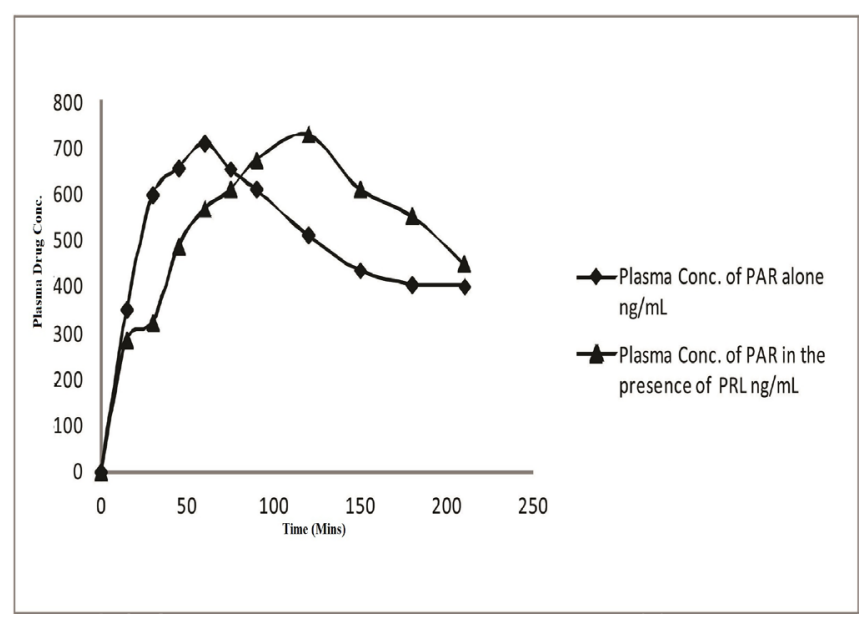

Figure 3: Plasma drug concentration of paracetamol alone and in paracetamol presence of propranolol hydrochloride

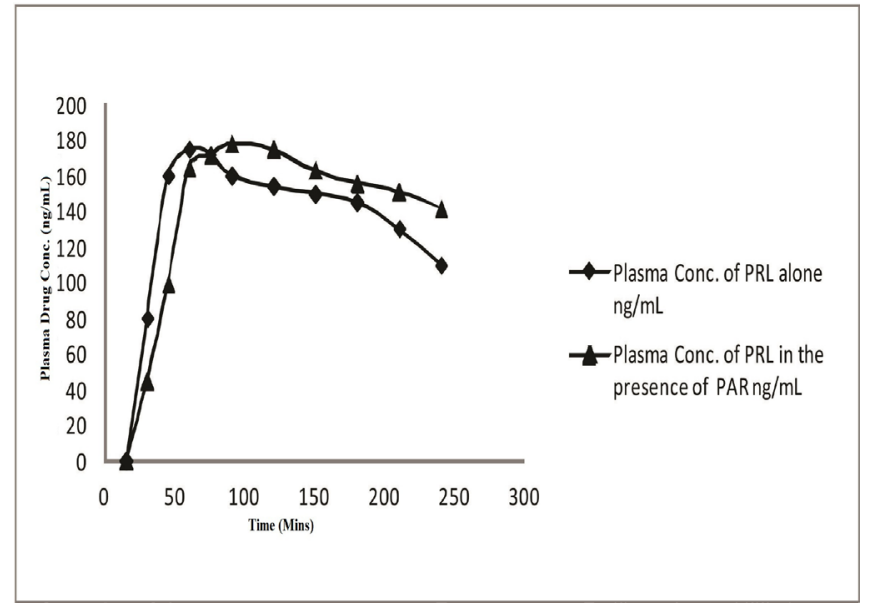

Figure 4: Plasma drug concentration of propranolol hydrochloride alone and in propranolol hydrochloride presence of paracetamol

Table 2: Pharmacokinetics data of Paracetamol and Propranolol Hydrochloride

\begin{tabular}{|c|c|c|c|c|}
\hline $\begin{array}{l}\text { Pharmacokietic } \\
\text { Parameters }\end{array}$ & Paracetamol & $\begin{array}{c}\text { Propranolol } \mathrm{HCl} \text { in the } \\
\text { Paracetamolpresence } \\
\text { of PRL }\end{array}$ & Paracetamol & $\begin{array}{l}\text { Propranolol } \mathrm{HCl} \text { in the } \\
\text { presence of Paracetamol }\end{array}$ \\
\hline$C_{\max }(n g / m L)$ & $710 \pm 11$ & $729 \pm 2$ & $175 \pm 1.9$ & $178 \pm 5.7$ \\
\hline$t_{\max }(\min )$ & $60 \pm 1.0$ & $120 \pm 4.5$ & $60 \pm 3.9$ & $90 \pm 2.2$ \\
\hline$t_{1 / 2}(\min )$ & $168.5 \pm 19$ & $134.5 \pm 15$ & $310.2 \pm 11$ & $450.3 \pm 10$ \\
\hline $\mathbf{K}_{\mathrm{el}}\left(\mathbf{h}^{-1}\right)$ & $0.0041 \pm 0$ & $0.0051 \pm 0$ & $0.0022 \pm 0$ & $0.0015 \pm 0$ \\
\hline$A C_{0 \rightarrow 3 h}(\mathrm{ng} \mathrm{h} / \mathrm{mL})$ & $75412.5 \pm 112$ & $52575 \pm 102$ & $26512.5 \pm 98$ & $24150 \pm 92$ \\
\hline $\mathrm{AUC}_{0 \rightarrow \infty}(\mathrm{ng} \mathrm{h} / \mathrm{mL})$ & $172935.4 \pm 178$ & $139932.2 \pm 145$ & $75742.97 \pm 138$ & $116403.7 \pm 102$ \\
\hline
\end{tabular}

However, the dissolution pattern of paracetamol when dissolved alone and in combination with propranolol hydrochloride showed almost the same results throughout the study period and the interaction was found to be statistically insignificant (Figure 2).

In vivo drug interaction study

By measuring the plasma drug concentration of one drug in the presence and absence of another in experimental Wistar rats shows that, at the first withdrawal of plasma (15 min), concentration of paracetamol was $350 \mathrm{ng} / \mathrm{mL}$ and paracetamol concentration when administered along with Propranolol Hydrochloride was found to be $284 \mathrm{ng} /$ $\mathrm{mL}$. Paracetamol reached its $\mathrm{T}_{\max }$ in 60 minutes with $\mathrm{C}_{\text {max }}$ of $710 \mathrm{ng} / \mathrm{mL}$ when introduced alone and when it was administered along with propranolol hydrochloride $t_{\text {max }}$ had doubled to 120 minutes. Their corresponding $\mathrm{t}_{1 / 2}$ were found to be 168 minutes and 134 minutes respectively, and their elimination rates were found to be $0.004 / \mathrm{hr}$ and $0.0051 /$ $\mathrm{hr}$ respectively. This result suggests the probable presence of drug interaction between paracetamol and propranolol hydrochloride in vivo with a p value of 0.086 (Figure 3).

Propranolol hydrochloride appeared in plasma at the end of 30 minutes when administered alone and in the presence of Paracetamol. Propranolol hydrochloride had reached its $\mathrm{T}_{\max }$ in 60 minutes with $\mathrm{C}_{\max }$ of $175 \mathrm{ng} / \mathrm{mL}$ when introduced alone and when it was administred along with paracetamol $\mathrm{T}_{\max }$ had increased to 90 minutes with $\mathrm{C}_{\max }$ of $178 \mathrm{ng} / \mathrm{mL}$. Their corresponding $\mathrm{t}_{1 / 2}$ was found to be 310 minutes and 450 minutes respectively, and their elimination rates were found to be $0.002 / \mathrm{hr}$ and 0.0015 / hr respectively (Figure 4). This result suggests the probable presence of drug interaction between paracetamol and propranolol hydrochloride in vivo with a $\mathrm{p}$ value of 0.99 . Pharmacokinetic parameters of the drugs are tabulated in Table 2.

\section{DISCUSSION}

In the present work of in vitro and in vivo drug interaction studies between paracetamol and propranolol hydrochloride, a significant delay in the dissolution of propranolol hydrochloride in vitro and plasma concentration of propranolol hydrochloride with a marked increase in its $T_{\max }$ in the presence of paracetamol was observed. Even a decrease in the $t_{1 / 2}$ of paracetamol in the presence of propranolol hydrochloride with decreased $\mathrm{AUC}_{0 \rightarrow 3 \mathrm{~h}}$ indicates the existence of drug interaction 
between propranolol hydrochloride and paracetamol. Also, there were considerable changes in the dissolution and a significant delay in the plasma concentration of paracetamol in the presence of propranolol hydrochloride with a marked increase in $\mathrm{T}_{\max }$ of paracetamol in the presence of propranolol hydrochloride was observed. To confirm the drug interaction, it was observed that $\mathrm{t}_{1 / 2}$ of propranolol hydrochloride was increased in the presence of paracetamol with increased $\mathrm{AUC}_{0 \rightarrow 3 \mathrm{~h}}$. Quick elimination of propranolol hydrochloride in the presence of paracetamol may suggest the competition amongst the substrates for the cytochrome enzyme as both are the substrates of the enzyme.

\section{CONCLUSION}

Drug interaction can lead to altered bioavailability, resulting in variations in the therapeutic efficiency of concurrently administered drugs. Based on the results of the present drug interaction studies, it can be suggested that caution is to be taken while administrating propranolol hydrochloride and paracetamol simultaneously. However, drug interaction study in human volunteers and migraine patients is required for dose altering of the drugs.

\section{ACKNOWLEDGEMENT}

Authors are thankful to The Principal, JSS College of Pharmacy, JSS University, Sri Shivarathreeshwara nagara, Mysore-570015 for providing research facilities.

\section{CONFLICT OF INTEREST}

The authors of the article declare no conflict of interest.

\section{ABBREVIATION}

$\begin{array}{lll}\mathrm{C}_{\max }: & \text { Peak concentration of drug in plasma } \\ \mathrm{t}_{\max }: & \text { Maximum peak time } \\ \mathrm{AUC}: & \text { Area under the curve } \\ \mathrm{K}_{\mathrm{el}}: & \text { Elimination rate constant } \\ \mathrm{Cl}: & \text { Clearance } \\ \mathrm{SD}: & \text { Standard deviation } \\ \mu \mathrm{g}: & \text { Microgram } \\ \mathrm{ng}: & \text { Nano gram } \\ \mathrm{nm}: & \text { Nanometer } \\ \mathrm{min}: & \text { Minute/minutes, hr: Hour/hours } \\ \mathrm{rpm}: & \text { Revolutions per minute } \\ \mathrm{mL}: & \text { Milliliter, } \%: \quad \text { Percentage }\end{array}$

\section{Highlights of Paper}

- Both in vitro and in vivo interaction were observed on drug interaction study between paracetamol and propranolol $\mathrm{HCl}$ and the interaction was statistically significant. The study suggests that during concurrent administration of these drugs, their dose is to be standardized and monitoring of plasma drug concentration is recommended.

\section{Author Profile}

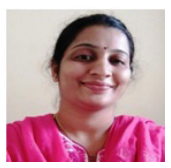

- Jyothigowdapura Channabasappa Thejaswini: Working as Assistant professor for Pharmaceutical Chemistry department at JSS University; JSS College of Pharmacy Mysuru. She has submitted thesis to obtain her Ph. D. degree to JSS University, Her research area of interests are drug interaction studies and analytical method development.

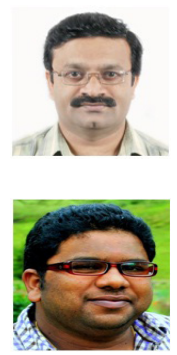

- Bannimath Gurupadayya: Currently working as a Professor in the Department of Pharmaceutical chemistry at the JSS college of Pharmacy, JSS University, Mysuru. He has obtained his Ph.D. Degree in 1996 from Kuvempu University, Shankaraghatta, Shimoga. His main research interests are in the areas of drug/herb interaction,chiral and herbal compound analysis.

- Venkata Sairam Koganti: Is a Research scholar at JSS University; JSS College of Pharmacy Mysuru, Where he graduated in Bachelor and Master of Pharmacy. His main research interests are in the areas of Analytical and Bio-analytical method developments for the pharmaceutical drugs and its validation. He has published widely in international journals and conferences. 


\section{REFERENCES}

1. Johnson MP, Fernandez F, Colson NJ, Griffiths LR. A pharmacogenomic evaluation of migraine therapy. Expert Opin Pharmacother. 2007; 8(12): 1821-5.

2. Ravishankar N, Demakis GJ. The neuropsychology of migraine. Dis Mon. 2007; 53(3): 156-61.

3. Thejaswini JC, Gurupadayya BM. RP-HPLC method development and validation for simultaneous determination of amitriptyline, carbamazepine and flunarizine in human plasma using mitrazapin as internal standard. Indo American Journal of Pharmaceutical Research 2014; 4(8): 2597-602.

4. Black JW, Crowther AF, Shanks RG, Smith LH, Dornhorst AC. A new adrenergic betareceptor antagonist. The Lancet. 1964; 283(7342): 1080-81.

5. Chung JM, Chung K. Importance of hyperexcitability of DRG neurons in neuropathic pain. Pain Pract. 2002; 2(2): 87-97.

6. Rick AW, Paul MK, Iva HB. Predictors of potential drug drug interactions. Hosp Pharm. 1998; 33(7): 835-40.

7. Viroj Wiwanitkit. Adverse drug reactions of nonsteroidal antiinflammatory drugs. J. Pharmacol and Pharmacother. 2011; 2(2): 132.

8. Stanton LA, Peterson GM, Rumble RH. Drug related admission to an Australian Hospital. J Clin Pharm Ther. 1994; 19(6): 341-7.

9. Swamy VKM, Setty RS, Shankaraiah MM, Jyothi TM, Rajendra SV. A study on drug-drug interaction of esomeprazole and anti-diabetic drugs. J Young Pharm. 2010; 2(4): 424-7.

10. Van $\mathrm{HH}$. Orbital sinus blood sampling in rats as performed by different technicians: the influence of technique and expertise. Lab Anim. 1998; 32(4): 377-86. 